\title{
Questões de (in)visibilidade: linguagem e trabalho
}

\section{Resumo}

Concebendo o visível em sua complexidade, em sua rede de inter-relações que faz brotar aspectos do invisível que lhe é constitutivo, temos como objetivo, nesta reflexão, discutir sobre a (in)visibilidade nas atividades de trabalho e de linguagem. Para tanto, com base na abordagem ergológica e na perspectiva dialógica, discorremos sobre três questões centrais: Quando se fala de (in)visibilidade do trabalho de que (in)visibilidade se está falando? Quando se fala de (in)visibilidade da linguagem de que (in)visibilidade se está falando? Como a perspectiva dialógica pode contribuir para acessar facetas da (in)visibilidade da atividade de trabalho?

Palavras-chave: (In)visibilidade. Linguagem. Trabalho. Alteridade. Dialogismo. Ética.

\section{Palavras iniciais}

Como facetas da mesma moeda, portanto dimensões indissociáveis, a visibilidade e a invisibilidade têm nos instigado a refletir, ainda com um grande espaço para aprofundamento, sobre questões de linguagem e trabalho. ${ }^{1}$ Afinal como o visível e o invisível se relacionam? Como a (in)visibilidade pode ser observada no trabalho? Como

\footnotetext{
* Doutora em Linguística Aplicada e Estudos da Linguagem pela PUCSP (2004), com doutorado-sanduíche (2001-2002) no Departamento de Ergologia da Université d'Aix-Marseille (França), e mestra em Letras (Estudos Linguísticos) pela UFSM (1998). Atualmente, faz pós-doutorado (PDE/CNPq) na Université Paris-Sorbonne sob a supervisão de Dominique Maingueneau. É professora-pesquisadora da PUCRS e editora da revista Letrônica (PPGL/PUCRS), tendo coordenado o Programa de Pós-Graduação em Letras entre 12/2012 e 03/2017. Integra a Société Internationale d'Ergologie (SIE), a Asociación Latinoamericana de Estudios del Discurso (ALED), a Association Analyse des Discours de l'Amerique Latine (ADAL), a Asociación de Lingüística y Filología de América Latina (ALFAL), a Associação Nacional de Pós-Graduação e Pesquisa em Letras e Linguística (ANPOLL) e a Associação Brasileira de Linguística (ABRALIN). Coordena o grupo Tessitura: Vozes em (Dis)curso (PUCRS/CNPq) e é pesquisadora do grupo Atelier Linguagem e Trabalho (PUCSP/ CNPq). É bolsista de Produtividade em Pesquisa do CNPq. E-mail: gdifanti@gmail.com
} 
pode ser observada na linguagem? Como a (in)visibilidade interfere na produção de sentidos?

Merleau-Ponty (2007, p. 224), em $O$ visivel e o invisivel, observa que "todo visível é invisível", ou seja, a visibilidade comporta em si mesma uma não visibilidade, o que permite dizer que o invisível não é "perfeitamente definido como um em-Si", uma "ausência objetiva". Para o filósofo, o

[...] invisível não é apenas não-visível (o que foi ou será visto e não o é, ou aquilo que é visto por outro diferente de mim, não por mim), mas onde sua ausência conta para o mundo (está por "detrás" do visível, visibilidade iminente ou eminente [...]) (p. 209). ${ }^{2}$

O invisível é constitutivo e não pode ser considerado como "outro visível 'possível', ou um 'possível' visível para outro: isso seria destruir a membrura que nos une a ele" (MERLEAU-PONTY, 2007, p. 210). Nesse contexto,

o invisível reside aí sem ser objeto, é a pura transcendência, sem máscara ôntica. E os próprios "visíveis" no final também estão apenas centrados sobre um núcleo de ausência (p. 211).

Concebendo o visível em sua complexidade, em sua rede de inter-relações que faz brotar aspectos do invisível que lhe é constitutivo, temos como objetivo, nesta reflexão, discutir sobre a (in)visibilidade nas atividades de trabalho e de linguagem. Para tanto, as discussões, embasadas na abordagem ergológica (SCHWARTZ, 2016a, 2016b, 2014, 2011) e na perspectiva dialógica (BAKHTIN, 2015, 2010; VOLOCHINOV, 2017, 2011), estão organizadas em três partes, seguidas das considerações finais, que respondem às seguintes questões: Quando se fala de (in)visibilidade do trabalho de que (in)visibilidade se está falando? Quando se fala de (in)visibilidade da linguagem de que (in)visibilidade se está falando? Como a perspectiva dialógica pode contribuir para acessar facetas da invisibilidade da atividade de trabalho?

\section{Quando se fala de (in) visibilidade do trabalho de que (in)visibilidade se está falando?}

A ergologia, abordagem pluridisciplinar voltada para o estudo da atividade humana de trabalho, ao observar que há uma saturação de normas antecedentes em todo agir humano, "concebe a atividade como uma trama de renegociações permanentes dessas normas" (SCHWARTZ, 2016a, p. 253). Tais renegociações caracterizam-se como

[...] uma possibilidade de viver com saúde cada encontro com o momento presente, momento sempre misto de sedimentações históricas e de circunstâncias inéditas (SCHWARTZ, 2016a, p. 254). ${ }^{3}$

Por essa compreensão, a abordagem ergológica concebe-se por um ponto de vista antropológico, "uma concepção do humano como ser de atividade: o que 
quer dizer, um ser em permanente debate de normas (renegociações) com seu meio de vida" (SCHWARTZ, 2016a, p. 254). Esse debate de normas visa

[...] atualizar [as] normas, sempre editadas em uma relativa intemporalidade, e as personalizar, pois elas se estabilizaram fora de toda consideração de sua singularidade como ser vivo.

Nesse contexto, Schwartz (2011, p. 34), em Conceituando o trabalho, o visível e o invisível, observa que, pela abordagem ergológica, toda atividade humana caracteriza-se "como um nó de debates entre normas antecedentes e tentativas de renormalização na relação com o meio". Esses debates, na atividade de trabalho, são

[...] frequentemente invisíveis, sustentados [...] sobre as normas operatórias, mas sem descontinuidade com as normas de vida que todo meio histórico veicula como misto de valores consensuais e valores contraditórios.

Nesse nó de debates, as normas antecedentes, por um lado, são "normas próprias a um meio humano, convocam todo um mundo histórico e social. É difícil de separar, de isolar as áreas de pertinência dessas normas", já que

[...] elas vão das mais distantes, das mais englobantes, como as normas jurídicas, o direito internacional, às mais próximas do agir presente, como por exemplo as normas prescritas (como dizem os ergonomistas) em meio de trabalho (SCHWARTZ, 2016a, p. 254).
Ou dito de outro modo, as normas correspondem não só a

[...] prescrições, procedimentos, constrangimentos, relações de autoridade, de poder, mas também a saberes científicos, técnicos, regras jurídicas, experiências capitalizadas.

Essas normas representam "tudo o que antecipe a atividade futura de trabalho, antes mesmo que a pessoa tenha começado a agir" (SCHWARTZ, 2011 , p. 34), logo as normas apresentam-se com graus de (in)visibilidade, pois, dada a complexidade da atividade, não é simples dimensionar o conjunto de normas que estão em relação com o fazer humano.

As renormalizações, por outro lado, dizem respeito às

[...] múltiplas gestões de variabilidades, de furos das normas, de tessitura de redes humanas, de canais de transmissão que toda situação de trabalho requeira, sem, no entanto, jamais antecipar o que elas serão, na medida em que essas renormalizações são portadas por seres e grupos humanos sempre singulares, em situações de trabalho, elas mesmas, também sempre singulares (SCHWARTZ, 2011, p. 34).

Assim, a atividade de trabalho é sempre singular, uma vez que os seres humanos, como industriosos, necessariamente, em maior ou menor grau, renormalizam suas práticas, atualizam as normas. Por isso, a atividade é considerada "sempre o lugar, mais ou menos infinitesimalmente, de reapreciação, de julgamentos sobre os procedimentos, os 
quadros, os objetos do trabalho, e por aí não cessa de ligar um vaivém entre o micro do trabalho e o macro da vida social cristalizada", instaurando uma dinamicidade que exige um olhar para seus múltiplos vaivéns (SCHWARTZ, 2011, p. 33). Por meio dos debates de normas, os protagonistas do trabalho sempre desfazem - de forma nem sempre aparente - "o impedimento do exercício 'do trabalho' deles mesmos, as perspectivas de vida que essas divisões propõem ou impõem" (SCHWARTZ, 2011, p. 35-36).

Conforme Schwartz, em entrevista a nós concedida, as normas antecedentes são necessárias "para viver em conjunto, para trabalhar juntos, para a vida social". No entanto, embora algumas atividades possam ter normas relativamente organizadas, contribuindo para uma vida comum saudável no trabalho, outras atividades podem ter normas que interferem negativamente nas práticas laborais. Um problema discutido, nessa perspectiva, diz respeito à falta de simetria entre as normas (primeira antecipação), que tem uma "legitimidade social, hierárquica, epistemológica" reconhecida, e os "saberes e valores emergidos na aderência do agir, aqui e agora" (segunda antecipação). Essa falta de simetria, chamada pelo ergólogo como "uma tendência permanente à usurpação", pauta-se na "crença de que os homens e mulheres podem agir mecanicamente sob subordinação das prescrições, dos saberes antecipados, das normas". Tal problemática cria crises, sofrimentos, problemas, que impõe a restituição de "uma postura parcial de simetria entre pessoas humanas, sem demagogia, porque sempre há necessidade de normas" (SCHWARTZ, 2016b, p. s225).

Os múltiplos debates, desenvolvidos "dialeticamente entre micro e macro, entre local e global”, põem em relevo a frágil visibilidade da atividade humana de trabalho, já que esses debates "são, em grande parte, não antecipáveis por qualquer que seja o modelo de interpretação científica". Há sempre no trabalho, como entende Schwartz (2011, p. 31),

[...] uma parte invisível ou uma penumbra. Crê-se, sem razão, saber de forma clara de que se fala quando, no entanto, todo "trabalho" comporta uma parte invisível provisória, na espera de uma eventual elucidação, e uma parte irredutivelmente enigmática.

Como antropologia, a abordagem ergológica "recusa toda determinação unilateral do agir humano por determinações histórico-sociais", já que os debates de normas são complexos e resultam de emaranhados de renormalizações, sempre locais, renovados incessantemente, impossíveis de serem antecipados. Cada trabalhador, ao renormalizar, leva em conta características da situação e também a maneira de conceber a saúde e a relação com o mundo de valor. Há, nesse âmbito, a singularidade de um corpo-si, que tem a sedimentação e a história de 
suas renormalizações, que, "a cada nova renormalização, mesmo que seja infinitesimalmente, reconfigura, (re)transforma um pouco esse corpo-si" (SCHWARTZ, 2016b, p. s228).

Para lutar contra a usurpação, segundo a abordagem ergológica, é necessário "criar uma dinâmica permanente de 'usinagem' das normas antecedentes", no sentido de retrabalhá-las considerando a segunda antecipação (renormalizações). Nesse sentido, são propostos Grupos de Encontro do Trabalho para, por meio do diálogo, dar visibilidade às "renormalizações e [às] razões das renormalizações, [aos] saberes ligados a essas renormalizações", elementos que podem levar a transformar as normas antecedentes. O que se percebe é que as renormalizações são bastante complexas e dinâmicas, constituídas de valores da vida social e política não previstos nas normas antecedentes, o que exige um trabalho de desvelamento, ainda que parcial, dada a complexidade dos nós de debates (Ibidem, p. s225).

A fim de conhecer as atividades humanas, o debate de normas e suas renormalizações, foi proposto o Dispositivo Dinâmico de 3 Polos (DD3P) como uma espécie de síntese da postura ergológica, que põe em relação dialética o polo 1 (antecipação 1) e o polo 2 (antecipação 2), visando focalizar, pelo diálogo e pela escuta, o agir humano sem mutilá-lo. ${ }^{4}$ O polo 3, como polo dos "valores epis- temológicos e éticos", tem a função de indicar "as condições humanas e sociais de funcionamento correto do trabalho entre os dois polos". Busca-se, ao mesmo tempo, tanto o reconhecimento dos valores dos saberes do polo 1 (pesquisadores, cientistas, quadros de lideranças das empresas etc.) quanto o reconhecimento dos valores dos saberes operacionais, os saberes-valores (SCHWARTZ, 2016b, p. s226). O polo 3 também tem o desafio de ser "um polo do mundo comum a ser construído", em que as pessoas aceitem trabalhar juntas, se respeitem mutuamente e que cada um faça um esforço para "construir um aprimoramento da situação comum" (escritório, empresa, associação, escola etc.) (SCHWARTZ, 2016b, p. s227). Embora não seja uma metodologia, o DD3P é "um ponto de partida, uma postura que apela à criação de métodos para dar visibilidade à atividade humana". ${ }^{5}$

A abordagem ergológica, como observa Durrive (2015, p. 192), funda-se sobre "a experiência humana do pensar e do viver", convidando a um diálogo dos saberes: "os saberes da organização que são rigorosamente destacados dos valores em jogo na atividade" e os saberes da atividade, que, ao contrário, "são sempre ligados aos valores, aos pontos de vista, aos debates de normas". Com o terceiro polo do DD3P, a ergologia propõe a mediação entre os polos da aderência e da desaderência, provocando a circu- 
lação e encontros dos saberes bem como autocríticas.

Por essa abordagem antropológica, como entende Schwartz (2016a, p. 255), as diferentes disciplinas convocadas pela ergologia devem respeitar as "exigências quase ontológicas fora das quais haveria perda da humanidade no [ser humano]", recusando qualquer "determinação unilateral do agir humano por determinações histórico-sociais”. Nesse contexto, Trinquet (2009, p. 176) destaca a importância da pluridisciplinaridade, já que nenhuma disciplina apresenta "a totalidade dos conhecimentos necessários para responder pertinentemente a todas as questões levantadas" por uma determinada atividade de trabalho analisada. Tais reflexões orientam para o fato de se recusar

[...] toda apropriação exclusiva do corpo-si por alguma disciplina que se recortaria aí com toda segurança um campo de estruturação autônomo (SCHWARTZ, 2016a, p. 255).

Esse conjunto de problemas põe em relevância aspectos sobre dimensões invisíveis da atividade de trabalho e os desafios de compreendê-la, tendo em vista o ser humano enigmático, base da sinergia - o corpo-si -, que, com experiências e saberes diversos, negocia permanentemente com as normas, via dramáticas de uso de si, pondo em relevo o impossível e o invivível. O corpo-si, de acordo com Schwartz (2014, p. 264), é composto por uma tríplice ancoragem indissociável: (a) biológica, refere-se ao corpo desde o nascimento, "com suas potencialidades e seus limites, [que] traz uma busca de saúde ainda genérica e indeterminada"; (b) histórica, instaura-se "mediante o debate de normas (por si/por outros) que constituem a própria substância dessas dramáticas e só adquirem sentido num momento particular da história"; e (c) singular, diz respeito à experiência de vida de cada um, das negociações "com um 'mundo de valores' que vai além dele, mais ou menos, a depender da pessoa". Cada pessoa, no debate de normas, obriga-se a escolher de novo, "a se reescolher como 'si', [questionando] as 'fidelidades' [que] levam o sujeito a retrabalhá-las em alguma medida", pois, por mais rotineira que seja, "a mesmidade é sempre retrabalhada", ainda que na invisibilidade (SCHWARTZ, 2014, p. 272).

Dentre as experiências de interfaces consideradas benéficas para o tratamento da atividade de trabalho, Schwartz (2016a), em Abordagem ergológica e necessidade de interfaces pluridisciplinares, destaca a ergonomia da atividade, as ciências da linguagem, a psicanálise e a neurociência. Contemplando a nossa área, as ciências da linguagem, passemos a discorrer, na próxima seção, sobre a perspectiva dialógica da linguagem, que também tem um viés antropológico ao considerar a língua/linguagem a partir da atividade humana em suas complexas relações. 


\section{Quando se fala de (in) visibilidade da linguagem de que (in)visibilidade se está falando?}

Bakhtin (2010, p. 44), em Para uma filosofia do ato responsável, ao questionar a divisão entre o mundo da cultura (geral, repetível) e o mundo da vida (particular, irrepetível), propõe a observação do ato ético responsável, um evento único do ser, como forma de superação dessa "perniciosa separação e a mútua impenetrabilidade entre cultura e vida". Para tanto, defende a necessidade de uma filosofia dedicada à compreensão dos atos do mundo da vida, na relação com $o$ mundo da cultura, de modo a discutir a eventicidade do ser e, consequentemente, aspectos relativos à sua complexa dinamicidade e inconclusividade, já que $o$ ato olha ao mesmo tempo, como um Jano bifronte, em duas direções opostas: "para a unidade objetiva de um domínio da cultura e para a singularidade irrepetível da vida que se vive" (BAKHTIN, 2010, p. 43). ${ }^{6}$

Por essas ponderações iniciais, já podemos observar o quanto o ato inscreve dimensões complexas, cuja percepção não necessariamente está no nível do visível. O ato ético, responsável e responsivo, nessa conjuntura, é baseado no reconhecimento da obrigatória singularidade, que se dá pela existência do ser e, consequentemente, sua impossibilidade de ser neutro: "É essa afirmação do meu não-álibi no existir que constitui a base da existência sendo tanto dada como sendo também real e forçosamente projetada como algo ainda por ser alcançado" (BAKHTIN, 2010, p. 99). Logo, "é apenas o não- álibi no existir que transforma a possibilidade vazia em ato responsável real", considerando o tom emotivo-volitivo e a responsividade: "ser realmente na vida significa agir, e ser não indiferente ao todo na sua singularidade" (BAKHTIN, 2010, p. 99).

O tom emotivo-volitivo "penetra em tudo o que é realmente vivido" e reflete "a inteira irrepetibilidade individual do momento dado do evento", revelando "as raízes da responsabilidade ativa" e a "verdade [pravda] do momento dado, o que o relaciona à unidade última, una e singular" (BAKHTIN, 2010, p. 92). Tal compreensão questiona a tese do racionalismo de que a verdade [pravda] só poderia ser "a verdade universal [istina] feita de momentos gerais", reproduzíveis, constantes, sem considerar "uma dada individualidade" (BAKHTIN, 2010, p. 92), ou melhor dizendo, sem considerar "a singularidade de uma totalidade absolutamente irrepetível" (BAKHTIN, 2010, p. 93).

Bakhtin $(2010,2003)$ propõe uma arquitetônica do mundo real, observável pelo ato ético que se configura a partir das seguintes relações de alteridade: 
eu-para-mim, outro-para-mim, eu-para-outro. Este "sistema de relações valorativas vitais básicas", como observa Bubnova (1996, p. 23), é concernente a todo ser humano em sua articulação com cada esfera de atividade humana, sendo $o$ ato ético

[...] o produto de interação do eu com o outro, interação que converte o ato em acontecimento do ser. Acontecimento do ser é um "ser junto", "um compartilhar a experiência do ser" (BUBNOVA, 1996, p. 25).

Na relação entre o eu e o outro, segundo Ponzio (2008, p. 193), "o outro produz a inquietude, a obsessão, a responsabilidade", que é a "condição ético-dialógica de ter que responder", própria da responsividade do ato. Nessa mesma direção, Faraco (2017, p. 52) observa que

[...] ser responsavelmente participante é realizar sua singularidade não para si, mas na relação com o outro. A interação é constitutiva [...] do mundo real do ato; e o outro, irredutível na sua diferença mas correlato com o eu, é a efetiva baliza do agir.

Tais considerações, como observa Faraco (2017, p. 48), dizem respeito ao primado da alteridade no pensamento bakhtiniano: "a absoluta necessidade constitutiva do outro, do olhar do outro, da memória do outro".

$\mathrm{O}$ ato bakhtiniano, conforme discute Bubnova (1996, p. 25), além de uma ação observável, ainda que altamente complexa, portanto, com graus de invisibilidade, também se materializa como "ato-visão, ato-pensamento, ato-senti- mento, ato-enunciado, ato de criação estética, ato de cognição etc.”. A noção de ato ético, nesse contexto, pressupõe uma atividade participativa, que circunscreve um centro de valor singular, heterogêneo, que age, vê, sente, experimenta, em suas múltiplas e complexas relações de alteridade constitutiva com o outro (centro de valor diferente) nas dinâmicas interações sociais (BAKHTIN, 2010, 2003). A singularidade do ser, própria do não-álibi na existência (emotivo-volitiva atuante), implica sua responsabilidade e participação no existir de modo irrepetível, único, insubstituível. Por isso, o eu, "como não álibi no ser, não está em relação reversível, invertível, simétrica com o outro", cada um é único na existência (PONZIO, 2016, p. 247).

Toda essa complexidade do ato, discutida por Bakhtin (2010, 2003), está alinhada à linguagem também como um ato concreto, enunciado vivo, discurso, um evento, cujas bases filosóficas dão sustentação a conceitos como alteridade e dialogismo, propriedades da linguagem. O texto do ato, como observa Zavala (1997, p. 182), "busca definir o outro, a alteridade, a outridade sob o signo da ética e da estética", o que entrelaça "a palavra e a alteridade, e as relações entre a palavra e o discurso".

Nesse cenário, Bakhtin (2010, p. 85) observa que a palavra viva, a palavra plena, não conhece um objeto como algo inteiramente dado, mas sim como criado, 
pois, "pelo simples fato de que eu comecei a falar dele, já entrei em uma relação que não é indiferente, mas interessado-afetiva”. A palavra, assim, expressa uma entonação, "a minha atitude avaliativa em relação ao objeto" e "movimenta-o em direção do que ainda está por ser determinado nele, torna-se momento de um evento vivo", concreto, o que marca a conjunção de outras valorações a que está conectado, está em relação (BAKHTIN (2010, p. 85-86).

$\mathrm{O}$ ato ético responsável, desse modo, pressupõe um "tom emotivo-volitivo" (entonação expressiva, expressividade, valoração, posição axiológica, acento de valor), que marca a atitude valorativa do sujeito face ao objeto do discurso e ao discurso do outro, também a relação entre o dito e o não dito, o verbal e o não verbal. Para Medviédev (2012, p. 185), o tom "dá cor à palavra do enunciado" em sua singularidade socio-histórica, ao mesmo tempo que indica que "a palavra é apenas um apêndice de outra presença” ( $p$. 190). A palavra alheia (discurso alheio) emerge no diálogo entre discursos e

[...] transforma nossa própria palavra em bivocal, ambivalente e polissêmica, converte a linguagem em um ponto de encontro de valorações (ZAVALA, 1996, p. 131).

Para a perspectiva dialógica da linguagem, o discurso, a língua em sua "concretude socioideológica viva" (BAKHTIN, 2015, p. 69), surge em um momento histórico e meio social determinado:

[...] não pode deixar de tocar milhares de linhas dialógicas vivas envoltas pela consciência socioideológica no entorno de um dado objeto de enunciação, não pode deixar de ser participante ativo do diálogo social (p. 49).

O discurso surge, pois, desse diálogo como uma réplica, uma resposta, que se forma "na interação dinâmica com o discurso do outro" (BAKHTIN, 2015, p. 52).

Nessa dinamicidade, como constitutivamente dialógico, o discurso se volta também para uma resposta, já que "não pode evitar a influência profunda do discurso responsivo antecipável" (BAKHTIN, 2015, p. 52). Assim, ao responder a enunciados passados e antecipar respostas, o discurso constitui-se por uma diversidade de vozes sociais (pontos de vista, visões de mundo etc.) nem sempre aparentes, advindas da permanente inter-relação com discursos outros.

Todo "discurso concreto (enunciado)", conforme Bakhtin (2015, p. 48), "encontra o objeto para o qual se volta sempre, por assim dizer, já difamado, contestado, avaliado, envolvido ou por uma fumaça que o obscurece ou, ao contrário, pela luz de discursos alheios já externados a seu respeito". Assim, o discurso entra num "meio dialogicamente agitado e tenso de discursos, avaliações e acentos alheios, entrelaça-se em suas complexas relações mútuas, funde-se com uns, afasta-se 
de outros, cruza-se com terceiros", o que aponta para sua constituição heterogênea com diferentes graus de (in) visibilidade.

Por mais que consigamos perceber discursos da trama do diálogo, sempre ficará uma parte a ser descoberta, dada a complexidade da produção discursiva, própria do vínculo entre a língua e a vida. De acordo com Volochínov (2011, p. 154), a palavra surge da situação extraverbal da vida e conserva com ela o vínculo mais estreito", já que "a vida completa diretamente a palavra", não podendo haver qualquer separação entre elas sob risco de perda de sentido. Nessa unidade indissolúvel, por conseguinte, as valorações sociais, sensíveis "para com qualquer oscilação da atmosfera social em torno do falante" (VOLOCHÍNOV, 2011, p. 160), marcam a relação entre a palavra e o acontecimento da vida:

[...] a palavra tomada isoladamente, como fenômeno puramente linguístico, não pode ser verdadeira, nem falsa, nem atrevida, nem tímida (VOLOCHÍNOV, 2011 p. 155).

É o tom, a entonação expressiva, o acento valorativo, atribuído por um sujeito dialógico em uma situação específica, que configura a palavra em enunciado, discurso.

Para Bakhtin (2015, p. 42),

[...] o autêntico meio da enunciação, no qual ela se forma e vive, é justamente o heterodiscurso dialogizado [...] concreto e rico em conteúdo e acentuado como enunciação individual.
Nesse meio, a palavra só se torna do falante quando ele "a satura de sua intenção, de seu acento" de modo a "comungar em sua aspiração semântica e expressiva"; antes disso, a palavra encontra-se, não em um dicionário, mas em "lábios alheios, em contextos alheios, a serviço de intenções alheias" (BAKHTIN, 2015, p. 69).

A língua não é um meio neutro, mas é res nullius, que passa fácil e livremente à propriedade intencional do falante: ela é povoada e repovoada por intenções alheias (BAKHTIN, 2015, p. 70).

Nesse cenário, o signo configura-se como ideológico e nele "cruzam-se ênfases multidirecionadas", instaurando um cruzamento de acentos, uma "multiacentuação", que, ao refletirem e refratarem a realidade, proporcionam "a capacidade de viver, de movimentar-se e de desenvolver-se" no meio social (VOLÓCHINOV, 2017, p. 113). Em tal conjuntura, a palavra é "um signo ideológico par excellence", sendo "o signo e sua situação social fundidos de modo inseparável" (VOLÓCHINOV, 2017, p. 135), o que faz com que a palavra seja sempre repleta de "conteúdo e de significação ideológica ou cotidiana” (VOLÓCHINOV, 2017, p. 181).

Tais características apontam para a constituição dinâmica e complexa do enunciado, discurso, que, como ato único do ser, está sempre em movimento, em processo, sendo o sujeito, em sua dialogicidade, constituído por 
[...] um agitado balaio de vozes sociais e seus inúmeros encontros e entrechoques [...] uma arena povoada de vozes sociais em suas múltiplas relações de consonâncias e dissonâncias (FARACO, 2009, p. 84).

Por essa perspectiva, o discurso, em sua pluralidade, heterogeneidade e multiacentuação, instaura-se singularmente a partir de distintos diálogos, característica importante para compreender que, além das aparências, há complexas relações (ainda que não resgatadas em sua totalidade) que devem ser consideradas para a compreensão dos sentidos. Essas observações são importantes para a discussão da próxima seção.

\section{Como a perspectiva} dialógica da linguagem pode contribuir para acessar facetas da (in) visibilidade da atividade de trabalho?

Considerando a complexidade das atividades de trabalho e de linguagem, cada uma com suas características próprias, passemos a discorrer sobre como a perspectiva dialógica pode contribuir para acessar facetas da (in)visibilidade da atividade de trabalho. Uma importante observação a ser feita recai sobre o fato de as duas visões terem preocupações filosóficas e antropológicas. Enquanto a abordagem ergológica, como observa Sch- wartz (2016a, p. 255), traz "interrogações filosófico-antropológicas" importantes para as diversas atividades humanas e, em especial, as atividades de trabalho, a perspectiva dialógica da linguagem, segundo Bezerra (2019, s/n), instaura a "elasticidade da temática filosófico-antropológica", que se sedimenta no dialogismo e abrange diferentes campos da atividade. A aproximação entre ambas, se, por um lado, pode facilitar a compreensão dos conceitos, por outro, põe em destaque o caráter enigmático do ser humano em suas práticas laborais e discursivas.

Na discussão levantada por Bakhtin (2010, p. 83) em seu texto sobre o ato, o filósofo da linguagem afirma que é impossível descrever o evento, em sua totalidade, por uma teoria afastada desse ato, uma vez que se perderia "o sentido mesmo de seu caráter de evento, $o$ sentido do que precisamente $o$ ato sabe de maneira responsável e a relação para a qual se orienta". Tal percepção aproxima-se das preocupações da ergologia, que reivindica a observação dos nós dos debates de normas, tendo como centro as renormalizações sempre inéditas. $\mathrm{Ou}$ seja, não se pode pensar na atividade de trabalho apenas pelas normas, sem considerar o agir industrioso no aqui e agora. Não se quer dizer com isso que somente se possa compreender o ato no momento da ação, mas sim que é necessária uma postura dialógica nesse ato de compreensão ativa responsiva. 
Um evento, conforme o pensador russo, "pode ser descrito somente de modo participante" (BAKHTIN, 2010, p. 84). Isso significa que há de se considerar que, no mundo-evento,

[...] nenhum objeto, nem uma só relação se dá aqui como simplesmente dado, como simplesmente, totalmente, presente; é sempre dado com alguma coisa a ser feita, a ser alcançada (BAKHTIN, 2010, p. 84-85).

Tal postura ressalta o valor da linguagem na difícil tarefa em exprimir “o existir-evento irrepetível e singular e o ato de que participa", tendo em vista que "uma plena adequação está fora do alcance, mesmo que ela permaneça sempre como um fim" (BAKHTIN, 2010, p. 84).

Para Bakhtin (2010, p. 85),

[...] no momento em que realmente vivo a experiência de um objeto - mesmo que apenas pense nele - o objeto se torna um momento dinâmico daquele evento em curso que é o meu pensá-lo-experimentá-lo.

O objeto "adquire, assim, o caráter de alguma coisa por se realizar, ou, mais precisamente, ele me é dado no âmbito do evento na sua unidade", instaurando momentos inseparáveis entre o "que é dado e o que está para se cumprir, o que é e o que deve ser, o fato e o valor". A relação estabelecida com o objeto, unidade viva, evento, convoca uma atitude avaliativa, que tem o caráter de um evento em processo.

Assim,
[...] compreender um objeto significa compreender meu dever em relação a ele [ ], compreendê-lo em relação a mim na singularidade do existir-evento: o que pressupõe a minha participação responsável, e não a minha abstração (BAKHTIN, 2010, p. 66).

Tal postura, na compreensão da atividade de trabalho, pode colaborar para se acessar facetas não visíveis do emaranhado de renormalizações. "Somente do interior de minha participação posso compreender o existir como evento", o que é importante para enfrentar os complexos debates de normas.

A criação de espaços de fala para o trabalhador pode ser produtiva para, a partir da experiência laboral, discorrer sobre as dramáticas vividas na atividade industriosa. O que temos de atentar, conforme discutimos no artigo Linguageme trabalho: diálogo entre a translinguística e a ergologia, publicado nesta revista em 2012 , é que, na verbalização sobre o trabalho, sempre há mudança das condições de produção do enunciado:

[...] [mudam] interlocutores, projeto enunciativo, tempo, espaço. Por exemplo, na experiência vivida, a interlocução acontece com determinados parceiros; na verbalização sobre a experiência, os interlocutores são outros, as posições assumidas são outras; o projeto enunciativo é outro. $\mathrm{O}$ que significa que dizer algo em um momento não tem o mesmo sentido se se disser exatamente a mesma coisa logo em seguida. São características da linguagem e sua natureza dialógica, a linguagem viva, dinâmica em um movimento de porvir (DI FANTI, 2012, p. 324). 
Essas particularidades estão alinhadas aos gêneros do discurso, formas discursivas com relativa estabilidade, que orientam a produção dos enunciados a partir das especificidades das esferas de atividade humana (BAKHTIN, 2016). Ter ciência dessas peculiaridades faz-se necessário, tendo em vista que todo enunciado, em maior ou menor grau, além de ter um projeto de dizer (mesmo que implicitamente), "responde, isto é, exprime a relação do falante com os enunciados do outro" (BAKHTIN, 2016, p. 58), por diferentes atitudes ativas responsivas ("concorda ou discorda dele[s], total ou parcialmente, completa-o[s], aplica-o[s], prepara-se para usá-lo[s] etc.”) (BAKHTIN, 2016, p. 25).

Nouroudine (2002) colabora com essa reflexão ao discorrer sobre a importância da linguagem para revelar aspectos da complexidade do trabalho. ${ }^{7}$ Apresenta, nessa perspectiva, três dimensões interdependentes: a linguagem como trabalho (linguagem operante, linguagem no aqui e agora da atividade), linguagem no trabalho (linguagem circundante, inclui a situação mais ampla) e linguagem sobre $o$ trabalho (linguagem que interpreta, que provoca reflexão sobre o agir). Temos de considerar assim que as interações variam, dentre outros fatores, conforme as normas antecedentes (mais ou menos distantes); os colegas de trabalho (mais ou menos próximos); as situações vividas (mais ou menos tensas); as posições hie- rárquicas (mais ou menos receptivas ao diálogo); e a presença de outra pessoa, externa ao meio (dependendo da finalidade dessa presença). A presença de um pesquisador, por exemplo, seja na situação laboral estrita, seja em situação de ouvir o trabalhador falar sobre o seu trabalho, vai influenciar, diferentemente, dependendo dos objetivos dessa presença, na composição dos enunciados. A verbalização sobre o trabalho (considerando também as dimensões no e como trabalho) em uma situação enunciativo-discursiva específica, sob esse enfoque, poderá facilitar a discussão sobre as dramáticas do corpo-si e revelar facetas do invisível da atividade de trabalho, mas isso vai depender de uma série de fatores, como é o caso da disposição do trabalhador participar da pesquisa, da relação de confiança entre o trabalhador e o pesquisador, da importância da pesquisa para o trabalhador e seu meio laboral etc.

Em qualquer enunciado estudado com mais profundidade - podemos incluir aí os produzidos como, no e sobre $o$ trabalho -,

[...] descobrimos toda uma série de palavras do outro semilatentes e latentes, de diferentes graus de alteridade. Por isso, o enunciado é representado por ecos como que distantes e mal percebidos das alternâncias dos sujeitos do discurso e pelas tonalidades dialógicas.

O enunciado, sob esse enfoque, é um "fenômeno muito complexo e multipla- 
nar", materializando-se como um "elo na cadeia da comunicação discursiva e da relação com outros enunciados a ele vinculados" (BAKHTIN, 2016, p. 60).

A colaboração da perspectiva dialógica para compreender a atividade de trabalho e facetas da sua (in)visibilidade vai ao encontro do entendimento de Schwartz (2016b, s229), que afirma que "nunca será possível apropriar-se totalmente da atividade dos nossos semelhantes, porque não podemos nos apropriar da vida mesmo". No entanto, podemos colaborar para "dessimplificar o trabalho, porque, por meio do trabalho, temos que dar visibilidade [aos] saberes-valores da segunda antecipação [vida industriosa] que têm que trabalhar com os saberes-valores da primeira", o que remete ao Dispositivo Dinâmico de 3 Polos e sua potencialidade de matriz a diferentes metodologias, como grupos de encontro do trabalho, instrução ao sósia, gravações e observações. Essa dessimplificação inclui o tratamento do trabalho como algo complexo, pois tratá-lo como simples "prejudica o reconhecimento de novas ideias, de sugestões para um novo mundo a ser construído" (SCHWARTZ, 2016b, p. s230).

A perspectiva dialógica, considerando as particularidades das diferentes metodologias e os gêneros do discurso mobilizados, atentará assim, se voltada para a expressão do trabalhador, para os aspectos enunciativo-discursivos verbo- -visuais em sua trama de sentidos. Uma entrevista, por exemplo, não pode ser considerada como um simples conjunto de perguntas e respostas, em que, para se saber algo, apenas bastaria perguntar para ter a informação almejada. A entrevista, a partir de um embasamento discursivo, como propõe Rocha, Daher e Sant'Anna (2004, não paginado), é um dispositivo enunciativo de produção de textos, em uma situação socio-historicamente particular, cujo diálogo travado entre entrevistador e entrevistado resulta em uma "co-construção dos referidos atores" e do "texto, construído a várias mãos”. A entrevista, desse modo, "mantém a distância entre a situação empírica e a situação discursiva", não podendo, portanto, ser considerada como a expressão fiel de uma dada realidade (ROCHA; DAHER; SANT'ANNA, 2004, não paginado).

Alinhada a essa perspectiva, faz-se necessário considerar a relação entre os sujeitos do discurso, como é o caso do entrevistador/pesquisador e do entrevistado/trabalhador, o projeto enunciativo, o tom emotivo-volitivo, o gênero discursivo, as variadas ressonâncias dialógicas de outros discursos, a situação histórico-social micro e macro, "os vestígios do direcionamento e da influência da resposta antecipável", dentre outros aspectos constitutivos do dizer, que podem auxiliar a desvelar características da (in)visibilidade do trabalho. Somente 
com uma concepção de linguagem que considere o ser humano em sua dialogicidade (não ficando no nível do aparente na superfície discursiva), reconhecendo, portanto, a constituição complexa e dialógica do enunciado, discurso, com diferentes níveis de (in)visibilidade, é possível também pensar nas (in)visibilidades de outros campos, como é o caso do laboral.

É importante considerar também, como entende Bakhtin (2010), que, na arquitetônica valorativa concreta, cada sujeito, como um centro de valor em relação-evento com outros sujeitos, ocupa um lugar único (espacial e temporal) e se constitui nas interconexões no evento único do ser. Em função da singularidade do lugar único ocupado, cada um tem um excedente de visão sobre o outro, ou seja, vê no outro o que ele sozinho não consegue ver:

o que em mim pode ser avaliado e compreendido apenas do ponto de vista do outro (a aparência em sentido amplo, o aspecto exterior, o habitus da alma, a totalidade da vida; acessível apenas a uma memória alheia sobre mim) (BAKHTIN, 2019).

Nessa arquitetônica, a relação entre empatia (aproximação) e exotopia (afastamento), dimensões indissociáveis, estabelecida entre centros de valores pode ser associada à relação entre o pesquisador e o pesquisado, em que se faz necessária uma aproximação do pesquisador ao outro de modo a reconhecê-lo em sua vivacidade, alguém com quem se fala, que provoca, questiona, responde, desafia..., para então, a partir de uma posição exotópica, distanciamento necessário, fazer aparecer graus de alteridade da palavra do outro. Tal encaminhamento revela uma postura ética que permite a construção do conhecimento e o reconhecimento do outro em sua singularidade, via um "excedente de visão" que propicia ver além do "todo" (BAKHTIN, 2003; AMORIM, 2001).

Essa reflexão vai ao encontro da noção de desconforto intelectual, que questiona a relação distanciada entre o saber acadêmico e o saber da experiência, dos valores dos interlocutores do mundo industrioso do trabalho. Tal cisão, invisível, é nociva "tanto para o saber conceitual (em desaderência), quanto para o mundo industrioso", criando "um problema quase de democracia" (SCHWARTZ, 2016b, s223). Ao se considerar "o agir humano como atividade, que é o conceito central da abordagem ergológica, a atividade sempre como um debate de normas", não se pode deixar de considerar o debate dinâmico, "de vai e vem permanente entre normas antecedentes e retrabalho/renormalização dessas normas" (SCHWARTZ, 2016b, p. s223).

Quando essa necessidade antropológica de debate entre os dois polos não é obedecida, cria-se "um desconforto intelectual para os que antecipam previamente o esquema do agir coletivo" (SCH- 
WARTZ, 2016b, s224). Isso acontece com os que criam "as normas antecedentes com certo grau de desaderência em relação à atividade, a qual sempre vive na aderência do presente aqui e agora". Além de ser um desconforto intelectual, é também "um desconforto social ou ético", uma vez que, "em qualquer renormalização, há uma dimensão de valor, sempre há uma escolha; quando há um debate, há uma escolha, e uma escolha se opera com valores", os saberes-valores, que devem ser iluminados.

\section{Considerações finais}

Discorremos, nesta reflexão, sobre três questões centrais relativas à (in) visibilidade do trabalho e da linguagem. No que se refere à primeira questão, Quando se fala de (in)visibilidade do trabalho de que (in)visibilidade se está falando?, tratamos da atividade de trabalho pela abordagem ergológica, que, dado o permanente "nó de debates", como observa Schwartz (2011, p. 34), entre normas antecedentes e renormalizações, instaura partes invisíveis, algumas enigmáticas, próprias das atividades humanas articuladas ao contexto histórico e seus valores multiacentuados.

No que diz respeito à segunda questão, Quando se fala de (in)visibilidade da linguagem de que (in)visibilidade se está falando?, tratamos da linguagem pela perspectiva dialógica, desenvolvida pelo Círculo de Bakhtin, que, ao ter como princípios básicos o dialogismo e a alteridade, pressupõe um conjunto heterogêneo e complexo de relações nem sempre visíveis. Nesse sentido, a linguagem, desde as primeiras obras, como Para uma filosofia do ato responsável (BAKHTIN, 2010), é considerada como atividade, e o enunciado, segundo Faraco (2009, p. 24), como "um ato singular, irrepetível, concretamente situado" que emerge de "uma atitude ativamente responsiva".

Quanto à terceira questão, indissociável das duas primeiras, Como a perspectiva dialógica pode contribuir para acessar facetas da (in)visibilidade da atividade de trabalho?, consideramos que tanto a atividade de linguagem quanto a de trabalho são constituídas por uma opacidade advinda da complexidade do ato humano, que pressupõe sentidos não visíveis a serem problematizados. Assim, somente uma concepção de linguagem que considere a construção dos sentidos em suas múltiplas inter-relações, para além do aparente, como é o caso da perspectiva bakhtiniana, poderá contribuir para dar visibilidade, ainda que em parte, por exemplo, às dramáticas do corpo-si, aos confrontos entre os saberes-valores e a infidelidade do meio em sua vivacidade, ao jogo entre o dito e o não dito, e às tensões entre o refletir e o refratar próprias da dialética dos signos ideológicos mobilizados na 
atividade industriosa do trabalhador (DI FANTI, 2012).

A partir das reflexões desenvolvidas, podemos dizer que, embora cada visão discutida - ergológica e dialógica - tenha seus próprios fundamentos epistemológicos, o olhar para as (in)visibilidades justifica-se diante da complexidade das atividades de trabalho e de linguagem. Pelo viés filosófico-antropológico de cada visão, circunscreve-se uma postura ética, responsável e responsiva, de abordar em sua singularidade - o corpo-si no/ do trabalho e o sujeito dialógico na/da linguagem. Tal postura implica, em sua base, relações de alteridade necessárias para o reconhecimento do eu e do outro.

Nessa dinâmica, como observa Miotello (2018, p. 35), o outro deve ser reconhecido como diferente, singular, não como uma réplica, uma generalização, que seria uma forma de dominação do outro e de impedimento do seu ato de pensar (que é também responsável e responsivo, convocado pelo outro). A linguagem, na constituição do eu e do outro, ocupa um papel fundamental:

[...] se há uma ética no discurso, é porque quando a linguagem passa entre um e outro, o que a gente está passando não são palavras [neutras], mas é eu mesmo.

O discurso, sob esse enfoque, instaura-se como uma ponte, um "lugar do encontro ético entre eu e o outro", sendo que a identidade "é construída pela fala do outro": "Eu vou saber quem eu sou me vendo nos seus olhos e não nos meus, porque nos meus olhos quem está é você". Desse modo, "as interações são absolutamente obrigatórias, elas são necessárias, a voz do outro precisa aparecer na minha própria voz" (MIOTELLO, 2018, p. 45).

Eis o papel da alteridade na construção ética do eu e do outro, na construção do discurso e na construção dos sentidos, caminho a ser observado pela perspectiva dialógica ao se dedicar a olhar facetas da (in)visibilidade da atividade humana de trabalho, reconhecendo um ser em processo, interconectado em múltiplas relações e alterado no evento do ato.

\section{(In)visibility Issues: language and work}

\section{Abstract}

We understand the "visible" as a complex interconnected network of relationships comprising aspects of invisibility that also emerge from it. Our purpose, thus, is to debate (in)visibility in work activities and in language. Based on ergology and on a dialogic perspective, we discuss three main questions: When we talk about work (in)visibility, what kind of (in)visibility do we mean? When we talk about language (in)visibility, what kind of (in)visibility do we mean? How can a dialogic perspective contribute to accessing (in)visibility features of work activities?

Keywords: (In)visibility. Language. Work. Otherness. Dialogism. Ethic. 


\section{Notas}

1 Di Fanti (2017a, 2012, 2004), Di Fanti e Kurz (2008), Barbosa e Di Fanti (2018) e Hinz e Di Fanti (2013).

2 Mantemos nas citações diretas, em todo a reflexão, os grifos utilizados pelos autores consultados.

3 Apresentamos reflexões sobre a formação da abordagem ergológica, que teve três grandes influências, Ivar Oddone, Alain Wisner e George Canguilhem, no artigo Linguagem e trabalho: diálogo entre a translinguística e a ergologia (DI FANTI, 2012).

4 O Dispositivo Dinâmico de 3 Polos, segundo Schwartz (2016b), começou a ser utilizado desde 1993.

5 Sobre o DD3P, ver Implicações axiológicas e a Escola sem Partido: (entre)olhares dialógicos e ergológicos (DI FANTI, 2017b).

6 Bakhtin, Volóchinov e Medviédev são os principais representantes dos estudos da linguagem do chamado Círculo de Bakhtin, cuja perspectiva dialógica fundamenta esta reflexão.

7 Souza-e-Silva (2014, p. 282), nessa direção, tem colaborado com importantes pesquisas sobre a relação linguagem e trabalho, em especial entre os estudos discursivos e ergológicos. A perspectiva discursiva adotada, por um lado, "implica considerar a língua não como instrumento informacional, transparente, mas como polissêmica e opaca”. A abordagem ergológica, por outro, "significa pensar a atividade de trabalho como o encontro entre as normas e os seres humanos capazes, por suas escolhas, de traduzi-las em cada situação".

\section{Refrências}

AMORIM, M. O pesquisador e seu outro: Bakhtin nas ciências humanas. São Paulo: Musa, 2001.

BAKHTIN, M. O homem ao espelho. Apontamentos dos anos 1940. Trad. Cecília M. Adum et al. São Carlos: Pedro \& João Editores, 2019.

BAKHTIN, M. Os gêneros do discurso. Org., trad., posfácio e notas de Paulo Bezerra. Notas da edição russa de Serguei Botcharov. Rio de Janeiro: Editora 34, 2016.
BAKHTIN, M. Teoria do romance I: A estilística (1930-1936). Org. da edição russa de Serguei Botcharov e Vadim Kójinov. Tradução, prefácio, notas e glossário de Paulo Bezerra. São Paulo: Editora 34, 2015.

BAKHTIN, M. Para uma filosofia do ato responsável (1920-1924). Trad. Valdemir Miotello e Carlos A. Faraco. São Carlos: Pedro \& João, 2010.

BAKHTINE, M. Pour une philosophie de l'acte. Trad. Ghislaine Bardet. Paris: Editions L'Age d'Homme, 2003.

BARBOSA, V. F.; DI FANTI, M. G. C. A (in) visibilidade da atividade de revisão de textos acadêmicos: um outro na teia dos sentidos. Letrônica, v. 11, p. s35-s53, 2018.

http://revistaseletronicas.pucrs.br/ojs/index. php/letronica/article/view/30803/17312

BEZERRA, P. Orelha. In: Brait, B., Pistori, M. H.; Francelino, P. F. (org.). Linguagem e conhecimento (Bakhtin, Volóchinov, Medviédev). São Paulo: Pontes Editores, 2019.

BUBNOVA, T. Bajtin en la encrucijada dialógica (datos y comentarios para contribuir a la confusión general). In: Zavala, I. M. (Coord.). Bajtin y sus apócrifos. Barcelona: Anthropos, 1996, p. 13-72.

DI FANTI, M. G. C. Discurso, dialogismo e atividade de trabalho: a constitutiva e tensa relação com o outro. In: Maria da Glória Corrêa di Fanti; Helena Nagamine Brandão. (Org.). Discurso: Tessituras de Linguagem e Trabalho. São Paulo: Cortez, 2017a, p. 89-126.

DI FANTI, M. G. C. Implicações axiológicas e a Escola sem Partido: (entre)olhares dialógicos e ergológicos. E-scrita, v. 8, n. 2, p. 65-75, 2017b. https://revista.uniabeu.edu.br/index. $\mathrm{php} / \mathrm{RE} / \mathrm{article} / \mathrm{view} / 2624 / \mathrm{pdf}$

DI FANTI, M.G.C. Linguagem e trabalho: diálogo entre a translinguística e a ergologia. Desenredo, v. 8, p. 309-329, 2012. http://seer. upf.br/index.php/rd/article/view/2651/1813 DI FANTI, M. G. C.; KURZ, C. A. Opacidade e produção de sentidos: atividade 
de linguagem e atividade de trabalho em diálogo. Revista de Estudos da Linguagem, v. 16 , n. 2 , p. $269-291,2008$. http://periodicos.letras.ufmg.br/index.php/relin/article/ view/2518/2470

DI FANTI, M. G. C. A constituição genérica do trabalho: problematizando rotinas e revelando hibridizações. Polifonia (UFMT), Cuiabá (UFMT), v. 8, p. 209-234, 2004. http:// periodicoscientificos.ufmt.br/ojs/index.php/ polifonia/article/view/1134/898

DURRIVE, L. L'expérience des normes. Comprendre l'activité humaine avex la démarche ergologique. Toulouse: Octarès Éditions, 2015 .

FARACO, C. A. Bakhtin e filosofia. Bakhtiniana, São Paulo, v. 12, p. 45-56, 2017. https://revistas.pucsp.br/bakhtiniana/article/ view/31815

FARACO, C.A. Linguagem \& diálogo: as ideias linguísticas do Círculo de Bakhtin. São Paulo: Parábola Editorial, 2009.

HINZ, J. R.; DI FANTI, M. G. C. O trabalho do professor-estagiário de língua portuguesa: uma atividade direcionada a quem?. Alfa: Revista de Linguística, v. 57, n. 1, p. 315-339, 2013. http://www.scielo.br/scielo.php?script=sci_ arttext\&pid=S1981-57942013000100014\&ln $\mathrm{g}=\mathrm{en} \& \mathrm{nrm}=\mathrm{iso} \& \mathrm{tlng}=\mathrm{pt}$

MEDVIÉDEV, P. (Círculo de Bakhtin). O método formal nos estudos literários: introdução crítica a uma poética sociológica (1928). Trad. Sheila Camargo Grillo e EkaterinaVólkova Américo. São Paulo: Contexto, 2012.

MERLEAU-PONTY, M. O visivel e o invisível (1964). Trad. José Artur Gianotti e Armando Mora d'Oliveira. São Paulo: Perspectiva, 2007.

MIOTELLO, V. Discurso da ética e a ética do discurso. São Carlos: Pedro \&João Editores.

NOUROUDINE, A. A linguagem: dispositivo revelador da complexidade do trabalho. In: Souza-e-Silva, M. C. P.; Faïta, D. (org.). Linguagem e trabalho: construção de objetos de análise no Brasil e na França. Trad. Inês
Polegatto; Décio Rocha. São Paulo: Cortez, 2002, p. 17-30.

PONZIO, A. No círculo com Mikhail Bakhtin. Trad. Valdemir Miotello et al. São Carlos: Pedro \& João, 2016.

PONZIO, A. A revolução bakhtiniana: o pensamento de Bakhtin e a ideologia contemporânea. Coord. de tradução Valdemir Miotello. São Paulo: Contexto, 2008.

ROCHA, D.; DAHER, M. D. C.; SANT'ANNA, V. L. A. A entrevista em situação de pesquisa acadêmica: reflexões numa perspectiva discursiva. Polifonia, v. 8, n. 8, 2004. http:// periodicoscientificos.ufmt.br/ojs/index.php/ polifonia/article/view/1132/896

SCHWARTZ, Y. Abordagem ergológica e necessidade de interfaces pluridisciplinares. $R e V E L$, edição especial, v. 14, n. 11, 2016a. http://www.revel.inf.br/files/1da5824c3c217 9f0e82728bf42da84f5.pdf

SCHWARTZ, Y. Uma entrevista com Yves Schwartz. Realização de Maria da Glória Corrêa di Fanti e Vanessa Fonseca Barbosa. Letrônica, v. 9, n. esp., 2016b, p. s222-s233. http://revistaseletronicas.pucrs.br/ojs/index. php/letronica/article/view/25359/15092

SCHWARTZ, Y. Motivações do conceito de corpo-si: corpo-si, atividade, experiência. Letras de Hoje, v. 49, n. 3, p. 259-274, 2014. http://revistaseletronicas.pucrs.br/ojs/index. php/fale/article/view/19102/12151

SCHWARTZ, Y. Conceituando o trabalho, o visível e o invisível. Trabalho, Educação e Saú$d e$, Rio de Janeiro, v. 9, supl. 1, 2011, p. 19-45. http://www.scielo.br/scielo.php?script=sci arttext\&pid=S1981-77462011000400002\&ln $\mathrm{g}=\mathrm{pt \& nrm}=$ iso\&tlng $=\mathrm{pt}$

SOUZA-E-SILVA, M. A interface estudos discursivos e estudos ergológicos. Letras de Hoje, PUCRS, Porto Alegre, v. 49, n. 3, p. 282289, 2014. http://revistaseletronicas.pucrs.br/ ojs/index.php/fale/article/view/19105/12153

TRINQUET, P. Prévenir les dégâts du travail: l'ergoprévention. Paris: PUF, 2009. 
VOLÓCHINOV, V. Marxismo e filosofia da linguagem: problemas fundamentais do método sociológico na ciência da linguagem (1929). Trad., notas e glossário de Sheila Grillo e Ekaterina Vólkova Aérico. São Paulo: Editora 34, 2017.

VOLOCHÍNOV, V. A palavra na vida e na poesia: introdução ao problema da poética sociológica (1926). In: Palavra própria e palavra outra na sintaxe da enunciação. Trad. Allan Pugliese et al. São Carlos: Pedro \& João Editores, 2011.

ZAVALA, I. Bajtin y el acto ético: una lectura al reverso. In: Bajtin, M. Hacia una filosofía del acto ético. De los borradores y otros escritos. Comentarios de Iris M. zaval y Augusto Ponzio. Trad. Tatiana Bubnova. Barcelona: Anthropos, 1997, p. 181-224.

ZAVALA, I. Bajtin y sus apócrifos o en el-nombre-del-padre. In: Zavala, I. M. (Coord.). Bajtin y sus apócrifos. Barcelona: Anthropos, 1996, p. 131-148. 